DOI: 10.12731/2658-4034-2020-1-20-24

\title{
ЗАКРЕПЛЕНИЕ УЧЕБНОГО МАТЕРИАЛА НА ДВУХ УРОВНЯХ УСВОЕНИЯ В ПРОЦЕССЕ ОБУЧЕНИЯ МАТЕМАТИКЕ
}

\section{Кисельников И.В.}

ФГБОУ ВО «Алтайский государственный педагогический университет», г. Барнаул, Российская Федерация

В статье отражены особенности организации закрепления учебного материала в процессе обучения математике в школе. Указань условия создания положительной мотивации к обучению на уроках математики. Вылелены отдельные типь заданий для закрепления учебного материала.

Ключевые слова: обучение математике; понимание учебного материала; усвоение учебного материала; закрепление знаний; мотивачия к обучению.

\section{SECURING EDUCATIONAL MATERIAL AT TWO LEVELS OF LEARNING IN THE PROCESS OF TEACHING MATHEMATICS}

\section{Kiselnikov I.V.}

Altai State Pedagogical University, Barnaul, Russian Federation

The article reflects the features of the organization of consolidation of educational material in the process of teaching mathematics at school. The conditions for creating a positive motivation for learning mathematics lessons are indicated. Separate types of tasks for consolidating educational material are highlighted.

Keywords: math education; understanding of educational material; learning material; consolidation of knowledge; motivation for learning. 
Этап отработки материала темы учащимися в процессе закрепления имеет приоритетное значение [1]. Учитель должен так организовать работу учащихся, чтобы в процессе выполнения предложенных им глубоко продуманных систем заданий все учащиеся: усвоили теоретический материал обязательного уровня, научились применять эти знания при выполнении определенных упражнений, задач, соответствующих требованиям, а затем на основе этого решать задачи повышенного развивающего уровня [2].

На протяжении всего этапа закрепления знаний и умений учащихся необходимо создавать условия положительной мотивации учения. Это достигается:

- предъявлением посильных требований в процессе работы учеников на этапе закрепления;

- предложением школьникам систем заданий, рассчитанных на разный темп отработки материала сильными, средними и слабыми учащимися, но выстроенных по принципу продвижения от простого к сложному;

- заинтересованным отношением учителя к работе учеников: своевременной помощью тем, кому она нужна;

- благожелательной оценкой достигнутого, постановкой решения новых задач.

Выполнение нескольких простейших заданий на прямое применение изучаемых сведений - определений, формул, правил и т.п. принесло бы на начальном этапе гораздо больше пользы, так как:

1) они позволяют включить в работу даже самых слабых учащихся.

2) при использовании простейших заданий легче прояснить и подчеркнуть смысл и мотивировку производимого действия.

3) для запоминания учеником правила большую роль играют возможности неоднократно его услышать и хотя бы раз проговорить его, а также использование моторной памяти, которая проявляется при письменном решении. Все это на начальном этапе закрепления более осуществимо при выполнении достаточного числа простых примеров.

4) с помощью простейших примеров можно усилить эффективность выполнения более сложных заданий, если использовать их как наглядные опоры. 
Таким образом, выполнение простейших заданий на начальном этапе отработки материала решает многие методические и педагогические задачи, важнейшая из которых - обеспечение посильной работой всех учеников, создание фундамента для успешного усвоения материала.

При организации закрепления материала необходимо уделить достаточное внимание заданиям обязательного уровня.

Задания обязательного уровня, с одной стороны, характеризуют тот материал, который должен быть прочно усвоен, по которому ученики будут подвергаться обязательной проверки, с другой - они часто представляют собой опорные блоки для выполнения сложных заданий и даже заданий творческого характера. Другими словами, отработка умений выполнять задания обязательного уровня важна и сама по себе, и как средство, способствующее более эффективному усвоению материала на повышенном уровне [3].

При отборе задач для закрепления материала необходимо предусмотреть достаточное число заданий разного характера.

1. Задания, направленные на формирование основных умений, которые должны выполнять все ученики (сюда должны войти и элементарные задания, и задания обязательного уровня).

2. Задания тренировочного характера на отработку обязательных умений для учеников, которая такая тренировка требуется.

3. Задания повышенного уровня для учеников, быстро продвигающихся в решении задач.

При закреплении темы можно организовать работу следующим образом. Всем ученикам раздаются задания обязательного и дополнительного уровня для закрепления по данной теме. Закрепление материала лучше начинать с совместной работы со всем классом. В ходе этой работы нужно обращать внимание учеников на приемы решения типичных задач, добиваться усвоения типичных рассуждений, требуемых для выполнения заданий. В дальнейшей работе по закреплению материала степень самостоятельности учащихся должна увеличиваться. При работе с заданиями обязательного уровня необходимо специально обращать на них внимание учеников. 
Учитель подчеркивает, что все должны уметь решать такие задачи. После выполнения заданий обязательного уровня учащиеся могут приступать к выполнению заданий дополнительного уровня. Такая организация работы способствует предотвращению погрешностей в предметных результатах обучения, проявляющихся в частности на государственной итоговой аттестации в форме ЕГЭ [4].

Для отработки материала с учетом индивидуального темпа овладения умениями можно использовать индивидуальные дополнительные задания продвинутого уровня ученикам, быстро справляющимся с работой (карточки с заданиями, номера из учебника) или индивидуальные задания для слабых учеников, испытывающих затруднения при работе на обязательном уровне (карточки, содержащие не только задания, но и обучающие элементы). Отработка материала осуществляется в условиях реализации процессного подхода к обучению математики [5].

\section{Список литературы}

1. Дорофеев Г.В., Кузнецов Л.В. и др. Дифференциация в обучении математике [Текст] // Математика в школе, 1990, №4.

2. Утеева Р.А. Дифференцированные формы учебной деятельности учащихся [Текст] // Математика в школе, 1995, №6.

3. Кулешова И.Г., Кисельников И.В., Брейтигам Э.К. Содержание фаз понимания учебного материала [Текст] // Science for Education Today. 2019. T. 9. № 5. С. 97-109.

4. Кисельников И.В. Методический анализ веера ответов участников ЕГЭ по математике // Фундаментальные науки и образование [Текст]: Материалы II международной научно-практической конференции / Алтайская гос. академия обр-я им. В.М. Шукшина.Бийск: ФГБОУ ВПО «АГАО», 2014. С. 424-427.

5. Кисельников И.В. Методический анализ результатов Единого государственного экзамена по математике профильного уровня в 2015 году в Алтайском крае [Электронный ресурс] // Современные проблемы науки и образования. 2015. № 5; URL: http://www.scienceeducation.ru/128-21580 (дата обращения: 10.09.2015). 
6. Кисельников И.В. Процессный подход в обеспечении качества обучения математике в общеобразовательной школе [Текст] // Мир науки, культуры, образования: научный журнал / Учредитель редакция журнала «МНКО». 2010, февраль, №1(20). С. 148-151.

\section{References}

1. Dorofeev G.V., Kuznetsov L.V. i dr. Differentsiatsiya v obuchenii matematike [Tekst] // Matematika v shkole, 1990, №4.

2. Uteeva R.A. Differentsirovannye formy uchebnoy deyatel'nosti uchashchikhsya [Tekst] // Matematika v shkole, 1995, №6.

3. Kuleshova I.G., Kisel'nikov I.V., Breytigam E.K. Soderzhanie faz poni-maniya uchebnogo materiala [Tekst] // Science for Education Today. 2019. T. 9 № 5. S. 97-109.

4. Kisel'nikov I.V. Metodicheskiy analiz veera otvetov uchastnikov EGE po matematike // Fundamental'nye nauki i obrazovanie [Tekst]: Materialy II mezhdunarodnoy nauchno-prakticheskoy konferentsii / Altayskaya gos. akademiya obr-ya im. V.M. Shukshina. Biysk: FGBOU VPO «AGAO», 2014. C. 424-427.

5. Kisel'nikov I.V. Metodicheskiy analiz rezul'tatov Edinogo gosudarstvennogo ekzamena po matematike profil'nogo urovnya v 2015 godu v Altayskom krae [Elektronnyy resurs] // Sovremennye problemy nauki i obrazovaniya. 2015. № 5; URL: http://www.science-education.ru/12821580 (data obrashcheniya: 10.09.2015).

6. Kisel'nikov I.V. Protsessnyy podkhod v obespechenii kachestva obucheniya matematike v obshcheobrazovatel'noy shkole [Tekst] // Mir nauki, kul'tury, obrazovaniya: nauchnyy zhurnal / Uchreditel' redaktsiya zhurnala «MNKO». 2010, fevral', №1(20). S. 148-151. 